\title{
JUSTIFICATION OF PARTICIPATION OF HUMAN SUBJECTS IN PHASE 1 CLINICAL TRIALS:
}

\section{AN ETHICAL ANALYSIS}

\author{
Dr. Inayat Ullah Memon \\ Chief Pathologist \& Incharge Bioethics Unit, \\ Peoples Medical College Hospital, Nawabshah, PAKISTAN \\ Email: memon.inayat@gmail.com
}

\begin{abstract}
In the process of clinical trials, after ascertaining the safety of drugs or other therapeutic interventions in animals or in vivo, phase I clinical trials are conducted as initial step on healthy human volunteers (or patients with specific disease) to observe pharmacokinetics, safety and side effects associated with escalating doses of the drugs.

Participation of human subjects having different biological system than animals is not without risks in these trials; this fact raises some important ethical issues. In the light of international research ethics guidelines, this paper analyses moral justification of use of humans as research subjects in phase I clinical trials, discusses what groups of participants should be involved, their economic status, questionable coercive effect of monetary remuneration on the subjects and soundness of informed consent obtained for the trials. These issues are also discussed in the perspective of four founding principles of bioethics i.e. autonomy, justice, beneficence and non-maleficence.
\end{abstract}

Keywors: Phase I trials, human subjects, ethics, participants' protection

Introduction: Tremendous development in medical science and consequent discoveries resulting into successful prevention and cure of various diseases are shared by the clinical research involving human participants. Preceding the trials in human subjects, to ensure safety the proposed drug or any other intervention is either tested in laboratory (in vitro) or in animals (in vivo) to assess initial safe starting dose for human beings and to identify the benchmarks for clinical monitoring for potential unfavourable effects. ${ }^{1}$ But these pre-human trials may not necessarily safeguard against untoward effects in human beings, as happened in case of thalidomide tragedy, which disabled and killed thousands of babies born to mothers taking this medicine. ${ }^{2,3}$ Use of healthy human subjects in preliminary experiments (phase I clinical trials) reduces or excludes the risks of subsequent unwanted effects in future trails and use in respective patients. Participants of phase I trials (or phase 0 trials) in some cases are the victims of such unpredictable and life-threatening effects as in case of TG1412. ${ }^{4,5}$ Apart from this ethically questionable situation, history of clinical trials reveals that either investigators or the research sponsors camouflaged the information conveyed the to prospective subjects or exploited either their social vulnerability or economic and intellectual poverty to lure them to the study. ${ }^{6,7}$ Regular and frequent visits by the researchers to specific geographic location on international level or particular communities within a country or region not only stigmatize them but target research subjects because of financial incentives offered to them rely on remunerations for their livelihood and welcome future researchers without need of knowing consequent ill-effects. Spirit of non-coercive and fully informed willingness does not absolve the researchers from the ethical responsibilities even when the documentary consent was obtained from participants, as participants have no knowledge of possible adverse effects of on-going research.

Cases of tainted consent in research negate the principle of respect for autonomy. Moreover the fact that there are only meagre probabilities of benefit to the participants of phase I trials, except the financial remuneration offered to them, while future users of that particular intervention would benefit from such trials, negates the principle of justice and beneficence. The principle of non-maleficence is violated when vulnerable groups of the communities are favourite subjects for the studies, resulting into their addiction for the participation in the trials with potential of harmful effects. This paper discusses following issues from ethical perspectives.

1. Whether is it justifiable to involve human volunteers in phase I trials?

2. If yes what groups of human volunteers be involved, casual participants or those who meet their living expenses from monetary remuneration or reward earned from such studies.

3. How much the subjects be paid for participating in these trials? Isn't the paid amount so voluminous that it deceives subjects' decisional capacity to participate? 
4. Issue of perception of phase I trials by the participants and ethical soundness of the obtained informed consent.

Justifiability of involving human beings: A necessary but not the sufficient requirement of justifying human involvement in clinical trials is that experiment has to be scientifically valid, based on reasonable hypothesis and should have a research methodology that can be expected to reach its stated endpoint. ${ }^{8}$ If we apply this requirement on phase I clinical trials (as well as phase 0 trials), then we do not have difficulty to justify the involvement of human models. But we have difficulty in meeting this requirement in oncology phase 0 trials as we do not have capabilities to measure the effects of the drug on its targets. Another requirement which is necessary and sufficient one to justify human involvement in clinical trials is that research needs to be of benefit to participants. Accepting the practices of clinical research the benefits include direct or indirect to participants and to others as well. ${ }^{8}$ The phase I trials carried out on healthy human volunteers are not coupled with any direct or indirect benefit to them. But those carried on patient volunteers such as suffering from cancer have a component (though a small one) of benefit to them directly as there is small chance of therapeutic benefit from these trials. Moreover the pro-phase I commentators may make their argument worthier and ethical by adding the factor of 'benefit to others' as a result if phase I trials prove successful. Additional component in favour of involving human models in these trials is participants' wish to help others (altruism).

What group of human beings should be involved: Careful selection of human participants is needed to justify their involvement in phase I trials to ensure avoidance of their exploitation. In the past, poor and desperate-formoney people were recruited to participate in these trials such as in Eli Lilly case, where homeless alcoholics were recruited for these studies. ${ }^{6}$ While in some other investigations, immigrants with doubtful health condition were recruited who later developed tuberculosis and contracted same to some others as well. ${ }^{7}$ Another factor augmenting exploitation is practice of involving for-profit Institutional Review Boards (IRB) as supervisory and overseeing bodies for the research trials. ${ }^{6}$

Monetary status of paid volunteers and volume of financial remuneration: A study carried out in recent past regarding socio-economic status of the participants revealed that financial incentive was one of the strong motivating factor as well as the most valued one for low income people while had no or opposite influence on people with higher earnings. Moreover lower educational level played a role to attract such people to participate in the phase I trials. ${ }^{9}$ To pay for participation in clinical trials is neither a new practice nor it is controversial. $^{6}$ Moreover it is not unlawful to offer payments for research participation. ${ }^{10}$ But core issue is the volume of the monetary need of the prospective phase I participants and the influence of financial inducement on various strata of the society resulting into possible deception of their decisional capacity. Same volume of money may not be tempting for a wealthy person but that could be very attractive for economically less privileged person of the society. ${ }^{6}$ This fact leads to the undue inducement for the participants and ethically undesired exploitation by the investigators or research sponsors. As a result, more will the chances that poorer become research participants and lesser will be the probabilities that they would benefit from such trials if the drug under question becomes available in the market (after successful trial and approval) but beyond the purchasing power of the poor. This situation negates one of the seven requirements (social value) of Ethical Research Trials ${ }^{9}$ and violates the article $19^{\text {th }}$ of the Declaration of Helsinki which requires that medical research is ethically justifiable, only if there is a reasonable chance that the population in which it is conducted will benefit from the results. Origin of some of these issues is based on the fact that clinical research has been changed into business adventure. As a consequence the research participants, taking part in phase I trials perceive it as a sort of job or employment. Their perception is not based on false beliefs but is truly based on offer of high remuneration for participation, which in many cases is more than minimum job wages and is consequently sufficient to mislead them. This situation also plays a part in distortion of medical history as because of temptation of disproportionately high incentives the prospective participants conceal their illnesses so as to avoid their disqualification from taking part in the trials. ${ }^{6}$ Beside the financial incentives for the participation in phase I trials there is ongoing discussion about relationship between the risks and hazards associated with phase I trials. Some commentators argue that not only the participants be paid but the volume of benefits and incentives be related to the degree of the risks. ${ }^{10}$ They argue that in today's rights-based society and value for individual autonomy it would be unduly paternalistic to set limits for financial inducements offered for the trials and they corroborate their position by the fact that monetary benefits do not affect the understanding of risks by the participants. ${ }^{10,11}$ An analogy has been offered by Jones and Liddell ${ }^{10}$ in this regard, where comparison of high-risk phase I trials is made with high-risk financial investments. I strongly disagree with their stance, contending that risk to life (or health) can't be legally and ethically compared with risk to financial investment, they are entirely different and unmatchable entities. Financial loss can be regained while human loss is irrecoverable. They also justify high incentives for risky and hazardous associated with phase I trials by exemplifying the high wages for dangerous industries or fire-fighting services ${ }^{10}$ Again, I argue against them, as in dangerous industries and fire fighting, the risks are more or less predictable and reasonably assessable, while in these trials the situation is entirely different. If it were the situation (predictability, even of high risk) in case of TGN1412 trials carried out by Parexel International, none of the six participants would have adventured to take part in the trials like this one, where their heads and necks swelled three times their normal 
size. ${ }^{12}$ I am with Saunders's opinion who rightly argue that 'level of the risk should not be so high as to necessitate payments in the first place'.13 Moreover the financial benefits offered should not be of such degree as to encourage people to take part in risky trials.

Perception by the phase I participants and soundness of informed consent: As has already been argued that poverty of the participants and the high financial benefits distort participants' perception as they take their involvement in the research trials as some sort of job., ${ }^{6,9}$ This misperception coupled with incomplete disclosure of the research risks and hazards, make the informed consent tainted with consequent disrespect and negation of the spirit embodied in the doctrine of informed consent.

Four Founding Ethical Principles Of Beauchamp And Childress And Phase I Clinical Trials: The four founding principles i.e. autonomy, beneficence, non-maleficence provide some valuable guidance in resolving the ethical issue of human participation in phase I clinical trials. Research participants are fully autonomous to take part (or not) by virtue of their self-governance but at the same time there should be some limits of governance. If the Western right-based society considers the 'right-to-die' as entirely and solely personal affair and confers this right to individuals such as in cases of euthanasia and PAS (Physician Assisted Suicide), then how many such countries have so far legally conferred their citizens the right-to-die? The situation is so such complex and controversial that in the Northern Territory (NT) of Australia, euthanasia legitimized by 'Rights of Terminally III Act 1995' was overturned by Federal Parliament just after 9 months of its enactment. ${ }^{14}$ While in other instances, because of difference of opinion amongst jurists, legal battles pertaining to mercy killing lingered for as long as seven years, as in case of Terri Schiavo. ${ }^{15}$ Therefore, supporting the issue of participating in phase I clinical trials with crunches of autonomy and self-governance is not without legal and moral weaknesses and shortcomings. Regarding the principle of beneficence; though these trials, meet the seven requirements of ethical conduct of the research set by Emmanuel et ${ }^{2}{ }^{16}$, but need balancing of the principles and rules as suggested by Beauchamp and Childress, keeping in view the nature of individual research. There is almost no benefit to the research participants in phase I trials except a minor fraction anticipated in those trials conducted on cancer patients. But benefit to others (for the society in future) provides reason for ethical justification of phase I trials. The scope and quantity of maleficence is low but its degree / severity might be high in some cases, like TGN 1412 cases. Depending upon the nature of cases, again decision should be made on case to case basis. One may infer from the basic notion of justice i.e. treating like situations in like ways, that no one should be preferentially or discriminately induced to take part in phase I trials. Then there should not be undue financial inducement or other forms of benefits for these trials to allure participants. Neither poor financial situation nor low educational level be exploited to tempt individuals to participate in these experiments. ${ }^{6}$ As the beneficiaries of the research results are the affluent people, therefore same group of people should offer themselves for the studies rather than guinea pigging the resource-starved communities.

Conclusion And Suggestion: There are no unequivocal guidelines by the international ethics organizations to set limits for the financial inducements offered to participations in research trials, particularly phase I. There are recommendations by some national organizations, but these are either vague or controversial such as those of British Pharmaceutical Industry (delinking benefits to the risks) and Royal College of Physicians (linking benefits to degree of inconvenience and incurring risks). There is need for some consensus principles on which Ethics Committees could base their decisions. There is need to set, define and explain the responsibilities of monitoring bodies engaged in overseeing the Phase I research trials, so that no such events occur in future like TGN1412, moreover establishment of for-profit IRBs should be discouraged in order to make justice with research participants. There is no disagreement with the fact that scientific, including medical knowledge can't grow without research including phase I trials, but tremendous scientific development requires balancing with increased sensitivity for bioethics with its broadened and deepened dimensions There is need to completely identify, understand and resolve these issues without the judges (such as bioethicist and members of IRBs and Review boards) being unduly influenced by the glamorous temptations offered by the some stakeholders such as powerful pharmaceutical. In these situations we need to protect the most vulnerable subjects of the research trials (phase I trials), particularly when their vulnerability is compounded by economic or intellectual poverty.

\section{References:}

1.Sellers EM, Souich PD, 'Phase I Trials' Human Pharmacology. http://www.iuphar.org/pdf/hum_40.pdf

\section{Thalidomide Victims Association of Canada, Thalidomide: The Canadian Tragedy} http://www.thalidomide.ca/the-canadian-tragedy/

3. The Thalidomide Tragedy: Another example of animal research misleading science http://www.pnc.com.au/ cafmr/online/research/thalid2.html 
4. Hawkes N, 'The Drug Trial that went horribly wrong', Sunday Times, March 16, 2006, http://www.timesonline.co.uk/tol/news/uk/health/article741405.ece

5. Suntharalingam G, Perry MR, Ward S, Brett SJ, Castello-Cortes A, Brunner MD, Panoskaltsis N, 'Cytokine Storm in a Phase 1 Trial of the Anti-CD28 Monoclonal Antibody TGN1412', New Eng J Med,Sept. 2006, vol. 355, pp. 1018-1028.

6. Elliot C, Abadie R, 'Exploiting a research underclass in phase 1 clinical trials', N Eng J Med, 2008, vol. 358, no. 22, pp. 2316-2317

7. Evans D, 'SFBC drug testers have tuberculosis after exposure at center', http://www.bloomberg.com/apps/news?pid=newsarchive\&sid=a90OZzPRIkaE\&refer=columnist_evansredirectoldpage

8. Hill TP, 'Phase O clinical trials: Are they ethically challenged?', Editorial, Clinical Cancer Res, 2007, vol. 13, no: 3, pp. 783-784

9. Almeida L, Azevedo B, Nunes T, Vas-da-Silva M, Soares-da-Silva P, 'Why healthy subjects volunteer for phase 1 studies and how they perceive their participation', European Journal of Clinical Pharmacology, 2007, vol. 63, no. 11, http://www.springerlink.com/content/0lu6704568434874/

10. Jone E, Liddell K, 'Should healthy volunteers in clinical trials be paid according to risk: Yes', 2009, BMJ, vol. 339, b4142

11. Bentley P, Thacker PG, 'The influence of risk and monetary payment on the research participation by healthy volunteers in clinical trials', J Med Ethics, 2004, vol. 30, pp. 293-298

12. Six Healthy Volunteers in Phase I Drug Trial Critically III UK, 2005.

<http://www.ahrp.org/cms/content/view/110/84/>

13. Saunders J, 'Should healthy volunteers in clinical trials be paid according to risk: No', 2010, BMJ, vol. 339, b 4145

14. Grey W, 'Right to die or duty to live? The problem of euthanasia', Journal of Applied Philosophy, 1999, vol 16, no 1 , pp. 19-32.

15. Quill TE, 'Terri Shiavo - A tragedy compounded', N Eng J Med, 2005, vol. 352, no. 16, pp. 1630 - 1633

16. Emmanuel JE, Wendler D, Grady C, 'What makes clinical research ethical', JAMA, 2000, vol. 283, no. 20, pp. $2701-2711$ 